\title{
Global endemicity centres for terrestrial vertebrates: an ecoregions approach
}

\author{
John E. Fa*', Stephan M. Funk \\ Durrell Wildlife Conservation Trust, Les Augrès Manor, Trinity, Jersey JE3 5BP, UK
}

\begin{abstract}
Endemic taxa are those restricted to a specific area, and can be defined as the exclusive biodiversity of a region. Areas with high endemic numbers are irreplaceable, and are of high priority for conservation. We investigated global patterns of endemicity of terrestrial vertebrates (mammals, birds, reptiles and amphibians) by employing data from World Wildlife Fund-US on 26452 species distributions (endemic and non-endemic) within 796 ecoregions. Ecoregions represent global ecosystem and habitat types at a landscape level. We explored the entire dataset by first using a principal components analysis, PCA, to identify which parameters and ordinations (transformations) best characterise the ecoregions. PCA identified the empirical logit transformation of proportional endemicity, not absolute or relative endemicity, as the appropriate variable. We prioritised ecoregions by ranking the empirical logit transformation of proportional endemicity, standardised across animal groups to avoid taxonomic biases. Finally, we analysed how ecoregion characteristics and the degree of isolation correlated with endemicity in all studied groups, by fitting logistic regression models. We argue that using our method, conservationists can better denote areas of importance for protection of endemic biodiversity worldwide.
\end{abstract}

KEY WORDS: Endemic species - Species richness - Terrestrial vertebrates - Ecoregions · Prioritisation · Isolation

Resale or republication not permitted without written consent of the publisher

\section{INTRODUCTION}

A variety of approaches has been used to assess biodiversity at different scales, employing prioritisation methods that differ widely in such aspects as representation, efficiency, functionality, international recognition, and benefits for people (Redford et al. 2003). Despite dissimilarities, most global prioritisation exercises focus on selecting areas with high (or highest) numbers of endemic species, such as biodiversity hotspots (Myers et al. 2000, Mittermeier et al. 1998, 2004), centres of plant diversity (WWF \& IUCN 1994-1997), and endemic bird areas (Stattersfield et al. 1998). Alternatively, other approaches concentrate on choosing areas of high species richness e.g. high-biodiversity wilderness areas (Mittermeier et al. 2003), megadiversity countries (Mittermeier et al. 1997), or Global 200 ecoregions (which also use endemism and other characteristics, see Olson \& Dinerstein 1998, 2002).
Endemism areas are responsible for high numbers of novel adaptations in species and communities, as promoted by geographical isolation (Erwin 1991, VaneWright et al. 1991, Rosenweig 1995, Spector 2002). A common approach for identifying high endemic areas is to count the number of endemics in distinct geographical areas (Brooks et al. 2006). However, the definition of an endemic species as 'a taxon confined to a certain region (and whose distribution is relatively limited)' is totally dependent on the land unit to which the species is restricted. The definition of area and area of endemism is critical to biogeographical thinking (Henderson 1991, Platnick 1991, Morrone 1994, Szumick et al. 2002). This is not trivial, since a different area definition could give a different result.

Prioritisation approaches involving endemics have used total numbers of endemics (e.g. plants in Myers et al. 2000), or some proxy of evolutionary processes by factoring out area size (Brummit \& Lughadha 2003, 
Brooks et al. 2006, Lamoreux et al. 2006). Instead of the a priori use of absolute numbers of endemics, Fa et al. (2004) applied principal components analysis (PCA) for birds and mammals in ecoregions in the Indo-Pacific region, to identify parameters and ordinations (transformations) that best characterise the ecoregions. PCA indicated that the 2 aspects of species diversity, species richness and endemicity, can be simultaneously accounted for. The components did not include absolute or percentage endemism, but a contrast between numbers of endemic and non-endemic species; these can be best modelled by the logit transformation, which linearises binomial data (Crawley 1993, Collett 2002). Furthermore, PCA also suggested that the logit transformation of endemicity scaled for species richness is better suited than absolute or percentage endemism to identify priority endemic areas in the IndoPacific region ( $\mathrm{Fa}$ et al. 2004). In the present paper, we expand and develop further analyses undertaken in $\mathrm{Fa}$ et al. (2004) to study patterns of endemism and species richness of terrestrial vertebrates worldwide. As in Fa et al. (2004), we employed World Wildlife Fund-US (WWF-US) ecoregions as a basic template of global natural units. Within these, we counted the number of terrestrial vertebrate species (mammals, birds, reptiles and amphibians) restricted to each ecoregion (endemics), and overall species numbers (species richness). Based on these data, we first used ordination techniques to confirm the relationship between species richness and endemicity as observed for the IndoPacific dataset in $\mathrm{Fa}$ et al. (2004). Then, to better understand the influence of ecoregion characteristics (area, realm, and biome) and geographic isolation (island, continent, montane, non-montane) on endemicity, we fitted logistic regression models to the data, by taxonomic groups, and for all taxa combined. Finally, using the results of the ordination, we prioritised ecoregions by ranking them according to their logit-transformed endemicity to detect global regions that can be considered as true global hotspots of endemicity for vertebrate species.

\section{MATERIALS AND METHODS}

Dataset. Ecoregions are geographical zones of regional extent that represent groups or associations of similarly functioning ecosystems (Olson \& Dinerstein 1998). Regional boundaries may be delineated on the basis of detailed information about ecosystems at the site level, or by analysis of environmental factors responsible for variation in ecosystems. WWF-US ecoregions are defined as a unit of land or water containing a distinct assemblage of natural communities and species, with boundaries that approximate the original extent of natural communities, prior to major land-use change (Olson \& Dinerstein 1998, Olson et al. 2001, Wikramanayake et al. 2002). Ecoregions emphasise the distribution of distinct biotas, yet these may not correspond either to zones of ecological potential which may have been determined by historical and chance events, or to the complex differentiation of living communities which is often due to subtle environmental conditions. Moreover, ecoregions may contain habitats from other than their assigned biomes (Olson et al. 2001). Despite these limitations, ecoregions constitute a powerful framework that is increasingly being used for conservation prioritisation (Olson \& Dinerstein 2002).

WWF-US currently divides the land surface of the Earth into 8 biogeographical realms with unifying features of geography, fauna and flora, and into 14 biome types, which are the major global plant communities determined by rainfall and climate. Nested within biomes and realms are 867 ecoregions. We used the complete WWF-US database on the distribution of all currently recognised terrestrial vertebrate species of mammals, birds, reptiles and amphibians within global ecoregions (J. F. Lamoreux pers. comm., WWF 2006), stratified whether endemic to a single ecoregion or non-endemic (i.e. occurring in more than one ecoregion). We included 796 out of the total of 867 ecoregions because species information for mangrove ecoregions was not available (Lamoreux et al. 2006).

To test the influence of geographical isolation on endemicity levels, we classified each ecoregion according to whether it was located on an island or continental area, and whether or not it was montane. In the present study, Australia was considered a continent and Greenland an island, based on the definition that a continent is an area of geologically stable continental crust (World Island Information 2006). Montane areas are described as regions with natural elevations of $>1000 \mathrm{~m}$.

Endemicity measure. Fa et al. (2004) used PCA to examine the relationship between number of endemics and species richness of birds and mammals in IndoPacific ecoregions. The first principal component (PC1, explaining $72 \%$ of the variance) represented a contrast (on the log-scale) between numbers of endemics and non-endemics, whilst PC2 $(20 \%)$ was a measure of overall species richness. Separate analysis for continental and island ecoregions identified the same ordinations, but with reversed associations between the principal components with endemicity and species richness. To confirm whether the Indo-Pacific observations were universal, we performed a PCA for all ecoregions, using total number of endemic species, and total number of species for birds, mammals, reptiles and amphibians, separately. The first 2 compo- 
nents of the global PCA accounted for $76 \%$ of the total variation $(\mathrm{PC} 1=47 \%, \mathrm{PC} 2=29 \%$ ). The resulting biplot and component loadings for the global PCA, shown in Fig. 1, indicated clear contrasts between species richness and endemicity. PC1 represents a meabetween species richness and endemicity. The relative the total Indo-Pacific data set (Fa et al. 2004), but they have the same direction as the continental subset in the Indo-Pacific. Because this PCA re-confirmed that the logit transformation best describes the endemic species dataset rather than absolute numbers or proportions of endemics, we used the following endemic-

$$
\ln \left(\frac{\left.E_{\text {ecoregion }}+0.5\right)}{S_{\text {ecoregion }}-E_{\text {ecoregion }}+0.5}\right)
$$

where $S_{\text {ecoregion }}=$ number of species and $E_{\text {ecoregion }}=$ number of endemic species in each ecoregion. To avoid difficulties with cases where $E=0$ or $E=S$, the customary practice is to use the empirical logit transformation, which adds 0.5 to both numerator and denominator (Collett 2002). sure of overall species richness and PC2 the contrast importance of these variables is reversed compared to ity measure:

When all taxa were jointly considered, the number of species and endemics were standardised across taxonomic groups in order to avoid taxonomic biases by

$$
\sum_{\text {taxa } t} \frac{E_{\text {ecoregion, } t}}{E_{\text {all }, t}} \times \sum_{\text {taxa } t} E_{\text {all,t }} \text { and } \sum_{\text {taxa } t} \frac{S_{\text {ecoregion }, t}}{S_{\text {all, } t}} \times \sum_{\text {taxa } t} S_{\text {all }, t}
$$

respectively, where $E_{\text {all, } t}=$ total number of endemics and $S_{a l l, t}=$ total number of all species in each taxonomic group $t$, respectively. Thus, absolute counts of endemic species were first logit-transformed and then taxonomically adjusted. The transformation and taxonomic adjustment together is termed 'corrected endemicity', and this term is used hereafter. Here, we use both the uncorrected logit transformation (logit endemicity) and the corrected endemicity. Absolute endemicity is the actual number of endemics counted for an ecoregion.

$\begin{array}{lcc}\text { Variable } & \text { PC1 } & \text { PC2 } \\ \text { Non-endemic mammals } & 0.373 & -0.397 \\ \text { Endemic mammals } & 0.257 & 0.408 \\ \text { Non-endemic birds } & 0.390 & -0.341 \\ \text { Endemic birds } & 0.188 & 0.538 \\ \text { Non-endemic reptiles } & 0.444 & -0.124 \\ \text { Endemic reptiles } & 0.342 & 0.365 \\ \text { Non-endemic amphibians } & 0.435 & -0.215 \\ \text { Endemic amphibians } & 0.351 & 0.275\end{array}$

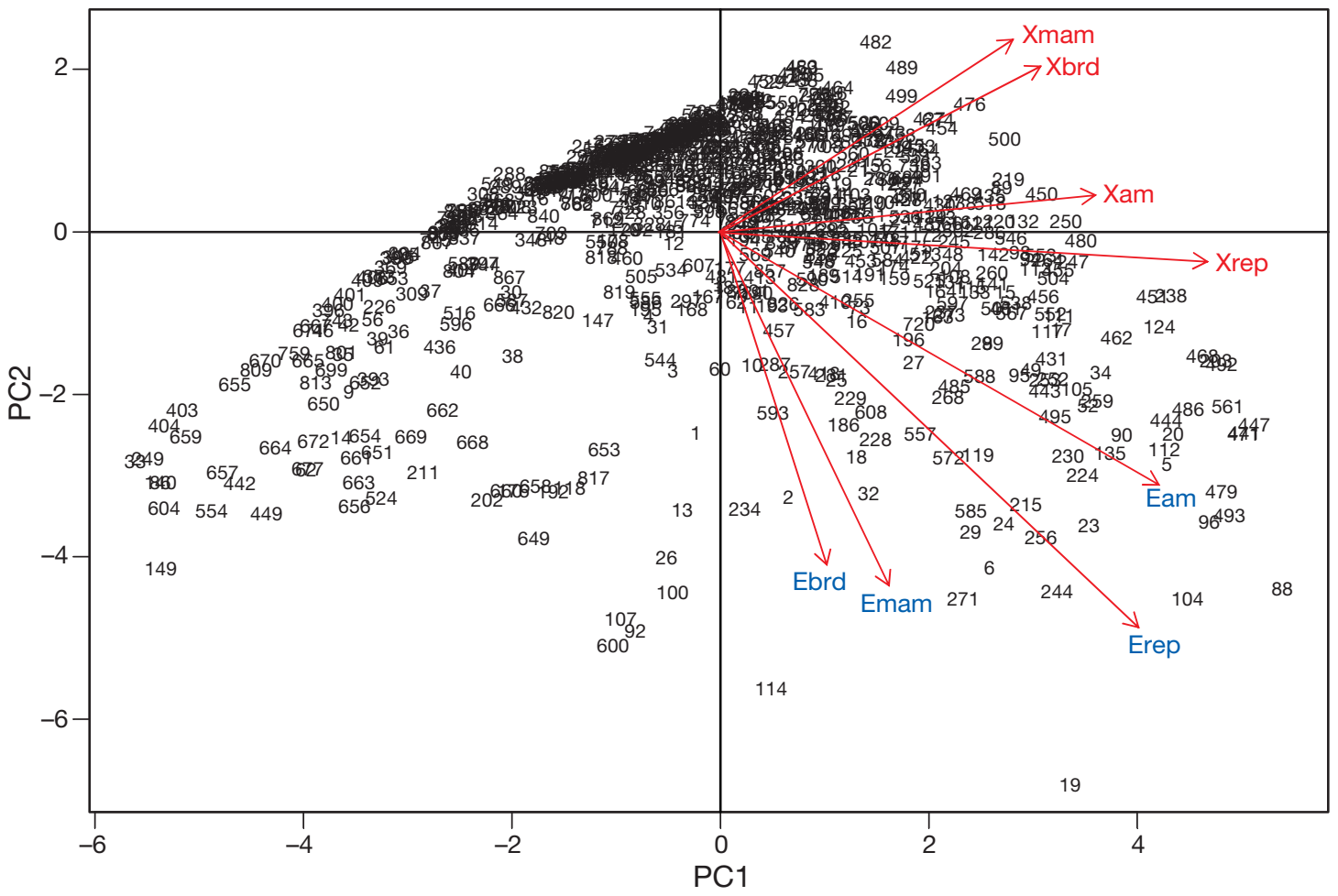

Fig. 1. Biplot of components 1 and 2 (PC1, PC2) of the PCA analysis of global endemic and non-endemic terrestrial vertebrates. The $x$-axis corresponds approximately to log richness (left: low richness, right: high richness), whereas the $y$-axis is approximately log endemicity, where endemicity is high at the bottom of the graph and low at the top of the graph. The numbered points are the ecoregions. Arrows represent the original variables and their lengths are a relative measure of their contribution to the overall variability in the data. The perpendicular projections of the arrows onto the component axes are the loadings of the corresponding variables. Emam: endemic mammals; Ebrd: endemic birds; Erep: endemic reptiles; Eam: endemic amphibians; Xmam: non-endemic mammals; Xbrd: non-endemic birds; Xrep: non-endemic reptiles; Xam: non-endemic amphibians 
Factors associated with endemicity. We first compared how logit-transformed endemicity in each taxonomic group correlated with absolute endemicity in the other groups using Pearson's correlation coefficients. Factors associated with corrected endemicity were then explored by binomial logistic regression models (McCullagh \& Nelder 1989) using the statistics package S-PLUS (Insightful Corporation 2001). Initial exploratory data analysis indicated overdispersion (variance greatly exceeding the expected binomial variance), so quasi-likelihood models were fitted allowing estimation of a dispersion parameter (McCullagh \& Nelder 1989). We included as explanatory variables: ln (area), realm, biome, island versus continental (coded as 1 and 0 respectively), and montane versus non-montane (coded as 1 and 0 respectively). To allow for the possibility of different effects in different realms, we also included interaction terms of map region with montane/non-montane, island/continental and biome. To allow for possible variations in dependency of endemicity on ecoregion size, we included interaction terms with ln (area). Models were fitted to data for all taxa combined and separately for each taxonomic group. Models were compared using analysis of deviance, using $F$-tests rather than the usual chisquare tests because of the estimated dispersion parameter. Ecoregions cannot be assumed to be statistically independent points for analysis, and spatial autocorrelation is expected to be highest within biomes and biogeographical realms. We accounted for this by including biomes and realms as explanatory variables, similarly to Lamoreux et al. (2006) who conducted geographically restricted randomisations constrained by both realm and biome. As we did not explicitly model spatial structure, we used an apostrophe to acknowledge the possible effect of spatial autocorrelation. Thus we use $F^{\prime}$ and $\mathrm{p}^{\prime}$ in order to estimate the relative importance of sources of variation rather than as statistical tests. We further used the results of F-tests, for cases with comparable degrees of freedom, to rank between explanatory variables.

Prioritisation of ecoregions. We ranked ecoregions according to their corrected endemicity values for all taxa combined. Taxonomically corrected species richness was used positively to sort tied ranks. We used the Top 100 and Top 200 ecoregions as arbitrary cut-off points.

\section{RESULTS}

Information on the 796 ecoregions and the species found within them, used in the present study, can be found in the 'Wildfinder' database (WWF 2006, Lamoreux et al. 2006). A total of 26452 species of terrestrial vertebrates, of which 6711 were endemics (734 mammals, 1415 birds, 2624 reptiles and 1938 amphibians) were used in our analyses.

\section{Factors associated with endemicity}

Correlation coefficients for absolute and logit-transformed endemicity between taxonomic groups are shown in Table 1. Logit-transformed endemicity explained consistently more of the variation between taxa (Pearson's $\mathrm{r} \pm \mathrm{SD}=0.55 \pm 0.10, \mathrm{R}^{2} \times 100=29.9 \%$ ), than absolute endemicity $\left(\mathrm{r} \pm \mathrm{SD}=0.34 \pm 0.13, \mathrm{R}^{2} \times 100\right.$ $=11.5 \%$ ). We observed no positive correlation between logit-transformed endemicity and size of ecoregions for birds $(\mathrm{r}=-0.16)$, mammals $(\mathrm{r}=-0.09)$, reptiles $(\mathrm{r}=-0.05)$, amphibians $(\mathrm{r}=-0.13)$ and all taxa combined $(\mathrm{r}=-0.05)$.

Results of logistic regression analyses for logit endemicity for all taxa combined, and for the 4 taxonomic groups separately, are shown in Table 2. Mean logit endemicity varied extensively with realm for all taxa combined, and each taxonomic group (Fig. 2). Box plots (Fig. 2), and estimated p'-values (Table 2) indicated that realm type is an important source of variation for all taxa combined, and for all taxonomic groups individually. Explanatory power as source of variation was particularly strong in birds and mammals, but relatively weak for reptiles and amphibians. Logit endemicity for all taxa combined, and for birds and mammals was markedly larger in Oceania than in other realms, whereas endemicity for amphibians and reptiles was similar across realms (Fig. 2). The importance of biome type as source of variation was lower than for realms, as indicated by smaller $F^{\prime}$-values despite higher degrees of freedom compared to realms (Table 2). Within taxa, biome types were more important for all taxa combined, as well as for birds and amphibians, whereas high $\mathrm{p}^{\prime}$-values $\left(\mathrm{p}^{\prime}>0.05\right)$ for reptiles and mammals indicated no or only relatively minor importance of biomes (Fig. 2). Tropical and subtropical moist broadleaf forests exhibited the highest

Table 1. Pearson correlation coefficients between logittransformed endemicity within vertebrate taxa. Below the diagonal are coefficients for logit-transformed endemicity. Above the diagonal are coefficients for absolute numbers of endemics

\begin{tabular}{|lcccc|}
\hline & Birds & Mammals & Reptiles & Amphibians \\
\hline Birds & & 0.50 & 0.29 & 0.36 \\
Mammals & 0.71 & & 0.26 & 0.17 \\
Reptiles & 0.46 & 0.45 & & 0.46 \\
Amphibians & 0.5 & 0.53 & 0.63 & \\
\hline
\end{tabular}




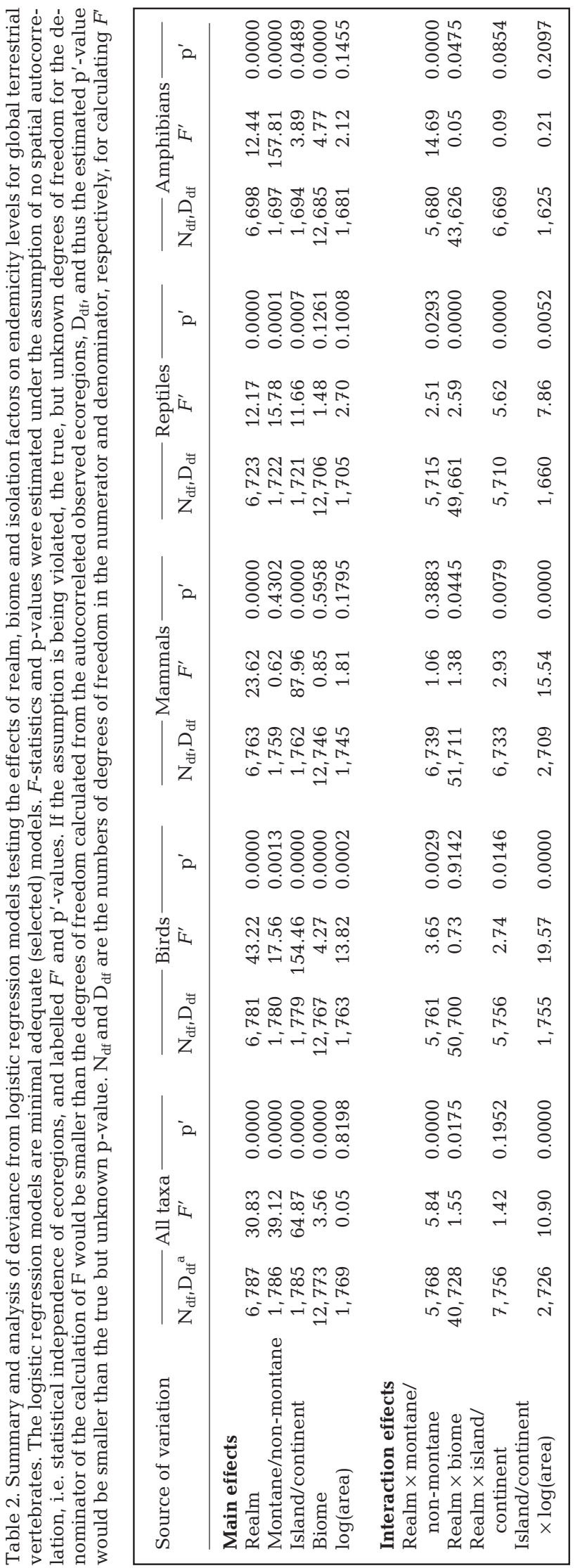

mean logit endemicity for all taxa combined, but also showed a very large variation; a trend also seen for birds and amphibians. Lowest mean corrected endemicity for all taxa combined was found in temperate grasslands, savannas and shrublands. Surprisingly, tundra had the highest mean logit endemicity in birds and amphibians, but not for all taxa combined. Interaction effects between biome and realm were low with relatively high $\mathrm{p}^{\prime}$-values (Table 2). Only mammals, reptiles and all taxa combined exhibited $\mathrm{p}^{\prime}$-values less than 0.05 .

After accounting for realm and biome effects, significant differences in logit endemicity appeared between island and continental ecoregions in all taxa and in all taxonomic groups when tested separately (Fig. 2). Island ecoregions exhibited higher logit endemicity than continental ecoregions. Only in amphibians was the island/continent distinction relatively unimportant ( $\mathrm{p}^{\prime}>$ 0.05 , Table 2 ). The montane versus non-montane contrasts were significant, except that the roles of amphibians and mammals were reversed (only mammals exhibited $\left.\mathrm{p}^{\prime}>0.05\right)$. $F^{\prime}$-values showed that the island/ continental dichotomy was significant for all taxa combined, and for mammals and birds compared with the montane/non-montane dichotomy ( $F^{\prime}$-values were double to 10-fold for the island/continental dichotomy). For reptiles and amphibians, the montane/ non-montane dichotomy was more important.

Interaction effects appeared between realm and island/continent and between realm and montane/ non-montane, but $\mathrm{p}^{\prime}$-values were in general relatively large, indicating weak sources of variation (Table 2).

Ecoregion area constituted an important source of variation only when taking the interaction with the island/continental contrast into consideration. For both island and continental ecoregions, there is an inverse relationship between logit endemicity and ln (area) for each taxonomic group and all taxa combined, but the effect is stronger for islands (steeper regression line) than for continents.

\section{Prioritisation}

Fig. 3 plots the empirical rank scores of species richness and corrected endemicity across all taxonomic groups for the 519 ecoregions that contain endemic species. We prioritised ecoregions according to absolute values of corrected endemicity, with positive values receiving highest ranks. The Top 100 and Top 200 ecoregions, with regard to endemicity (Appendix 1, available as Supplementary Material at www.int-res.com/articles/suppl/n003p031_app.xls), constitute 12.6 and $25.2 \%$ of the 796 analysed terrestrial ecoregions, respectively. They under-represent 

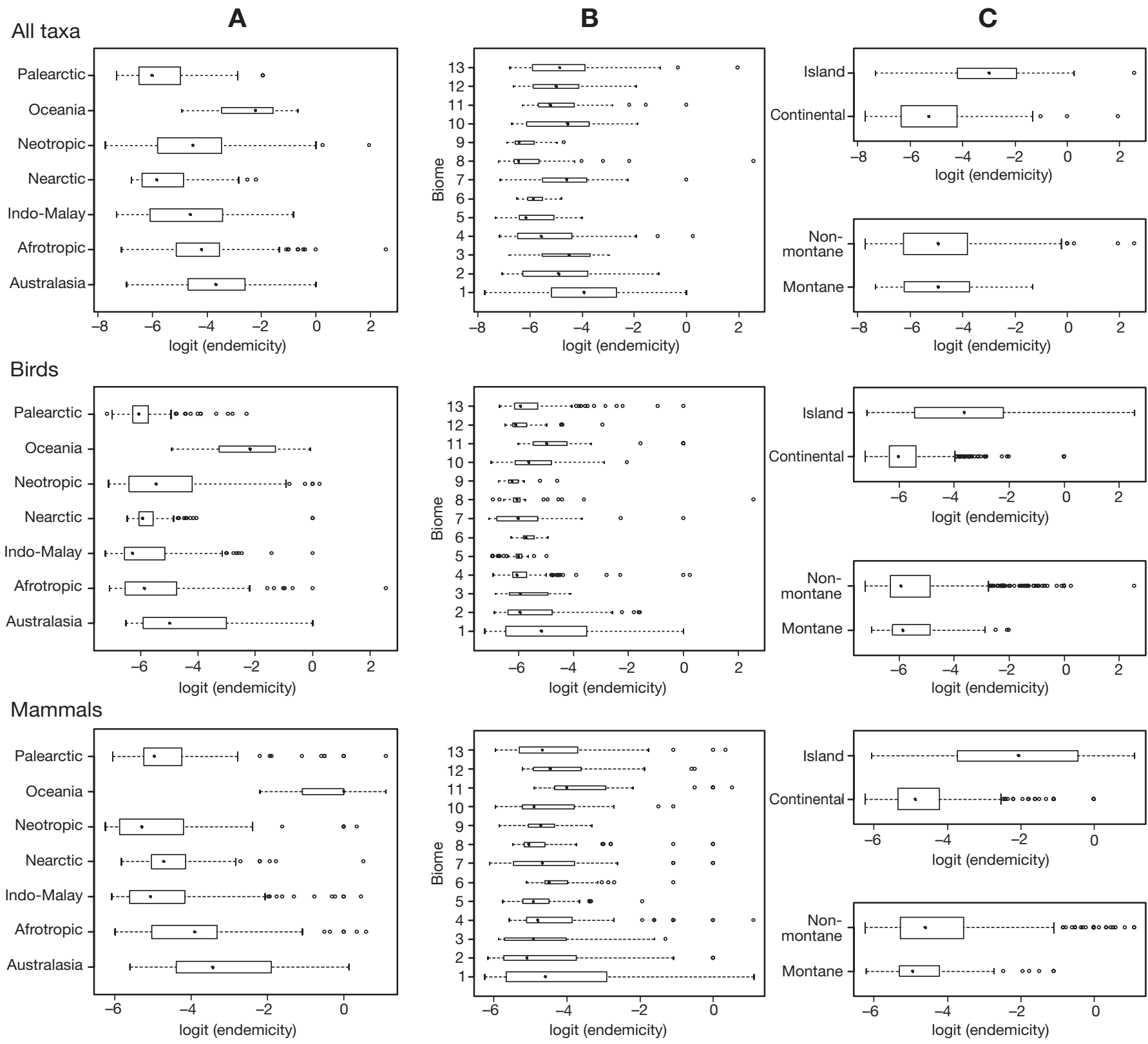

(continued on next page)

area size ( 4.7 and $17.5 \%$ of total area, respectively), but over-represent endemic species of birds: 70 and $85.3 \%$; mammals: 48 and $76.4 \%$; reptiles: 42 and $68.3 \%$; amphibians: 47 and $76.1 \%$; and all endemics: 50 and $75.1 \%$,: Fig. 4A). The Top 100 included the 5 ecoregions that harboured more endemic than nonendemic species and thus had positive corrected endemicity values. They are biased towards ecoregions that combine the highest corrected endemicity and lowest taxonomically corrected species richness (top left in Fig. 3).

High-priority ecoregions strongly over-represent islands but under-represent only slightly montane eco- regions (Fig. 4B). The Top 100 and Top 200 include 70 and 90 island ecoregions, respectively, and represent 49.0 and $63.0 \%$ of all islands. In contrast, the lowerpriority ecoregions rarely represent islands, with the exception of the large proportion of islands amongst the bottom 100 (14 islands, representing 9.8\% of all islands). None of these low-priority islands contains known endemic bird, mammal, reptile or amphibian species and they are generally species-poor (mean species richness of $6.6 \pm 1.5$ and $4.4 \pm 1.2$ in the top 100 and bottom 100 ecoregions, respectively).

The Top 100 and Top 200 ecoregions include 16 and 49 montane ecoregions, respectively, and represent 

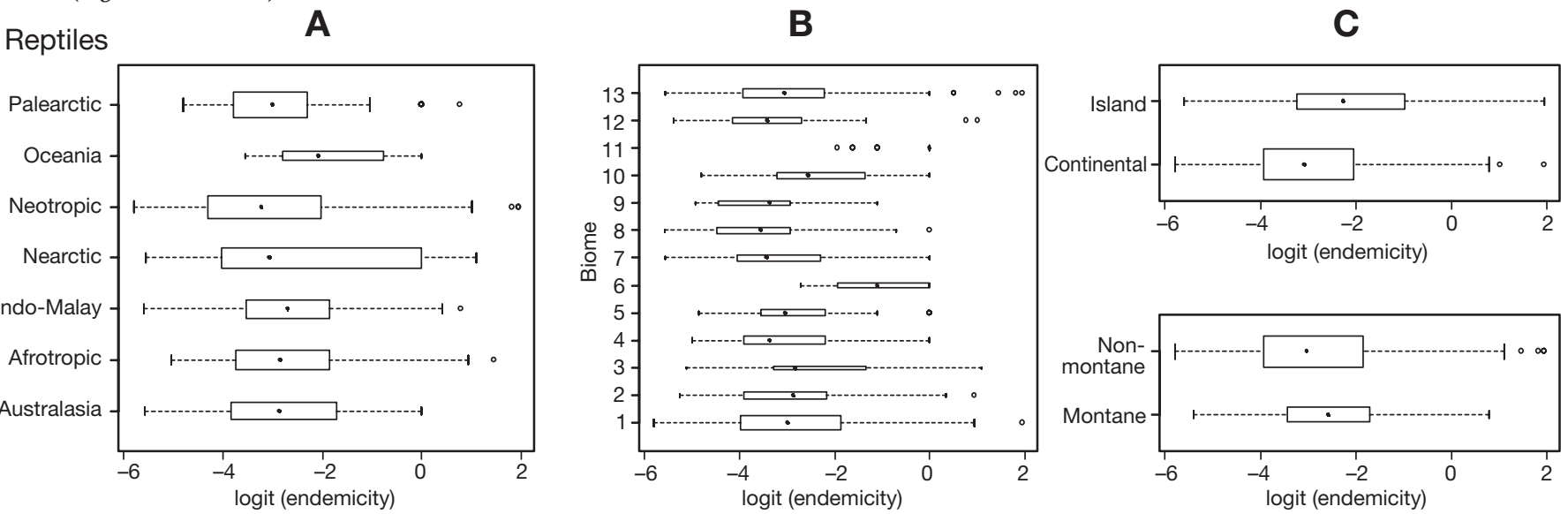

\section{Amphibians}
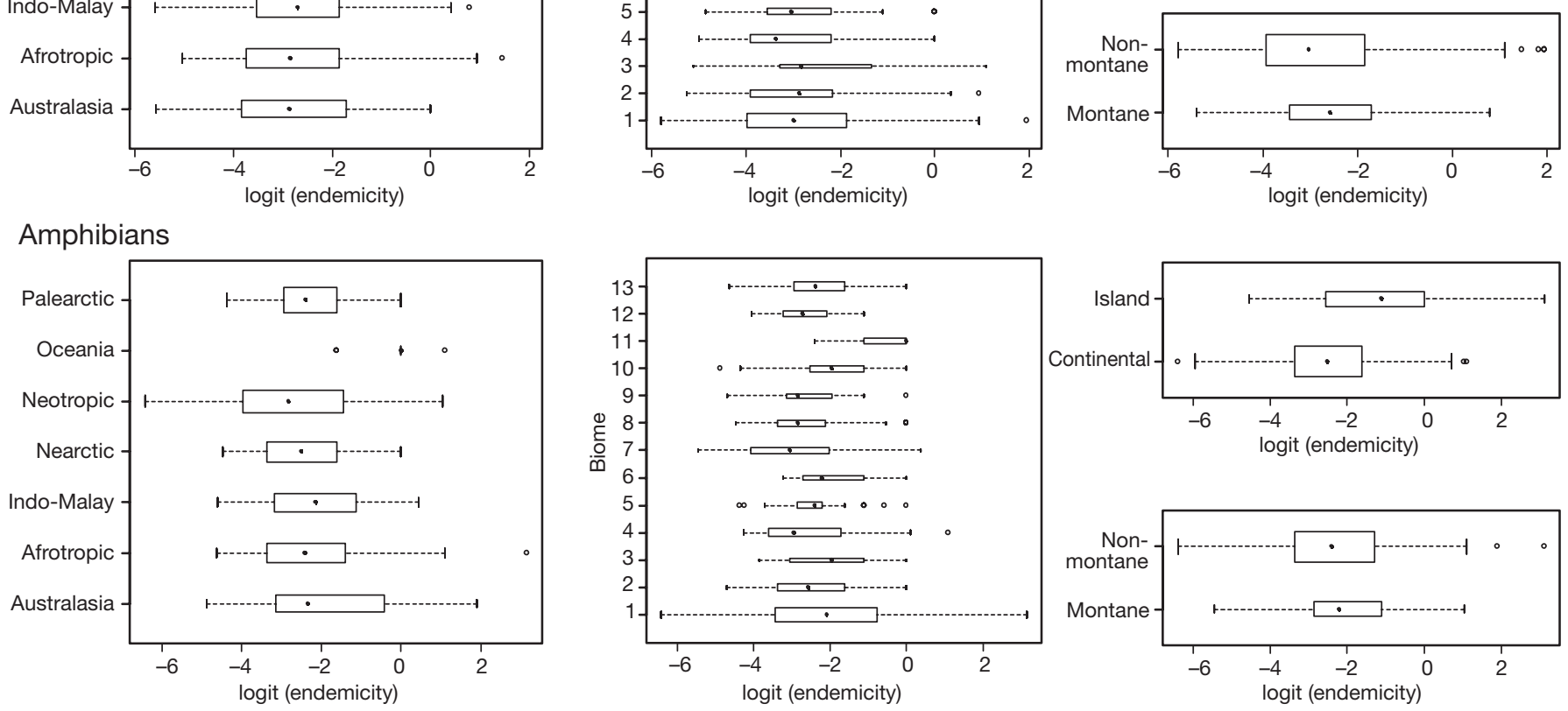

Fig. 2. Box plots of logit endemicity levels for global terrestrial vertebrates for all taxa pooled, and individual taxonomic groups, according to: (A) biogeographical realms, (B) biome type, and (C) isolation factors, grouped by whether or not the ecoregion is situated on an island or continental mass (island/continent), or on a montane or non-montane area. Biome types are 1: tropical and subtropical moist broadleaf forests; 2: tropical and subtropical dry broadleaf forests; 3: tropical and subtropical coniferous forests; 4: temperate broadleaf and mixed forests; 5 : temperate coniferous forests; 6 : boreal forests/taiga; 7 : tropical and subtropical grasslands, savannas, and shrublands; 8: temperate grasslands, savannas, and shrublands; 9: flooded grasslands and savannas; 10: montane grasslands and shrublands; 11: tundra; 12: Mediterranean forests, woodlands, and shrub; 13: deserts and xeric shrublands

9.4 and $28.7 \%$ of all montane ecoregions. By realm, the Top 100 and Top 200 ecoregions over-represent Oceania (62.5 and $70.8 \%$ ), Australasia (28.0 and $45.1 \%$ ), Afrotropics (16.0 and 40.6\%), Indomalay (16.0 and $29.9 \%$ ) and Neotropics (12.6 and $28.7 \%$ ), whilst the Palearctic (2.5 and $8.1 \%$ ) and Nearctic (1.7 and $7.6 \%$ ) are under-represented. The Bottom 100 over-represent the Nearctic (33.6\%), Oceania $(25.0 \%)$, and Palearctic $(20.3 \%)$ and under-represent Australasia (7.3\%), Indomalay $(4.0 \%)$, Afrotropics $(2.8 \%)$ and Neotropics $(0.6 \%)$. The global distribution of all ranked ecoregions is shown in Fig. 5.

\section{DISCUSSION}

The concept of sites or centres of high diversity or endemicity has attracted the attention of conservation- ists as a tool for helping determine which areas should receive priority attention. Choosing areas of diversity as opposed to those of endemicity may turn up different regions for protection. This is so because species endemism and richness are not linearly related with area size, but the relationship is a power function (Brummit \& Lughadha 2003). On the other hand, because any area containing endemics is irreplaceable, it can be argued that it is the total number of endemics that is the most important aspect for biodiversity conservation. However, whether the focus is on observed patterns (total number of endemics), evolutionary processes of biodiversity (density of endemics), or biological factors instead of a combination of biological and social and economic factors (Shi et al. 2005), the choice of method for prioritising nature is based ultimately on particular values and goals that a person, and/or an organisation may have, and these should be 


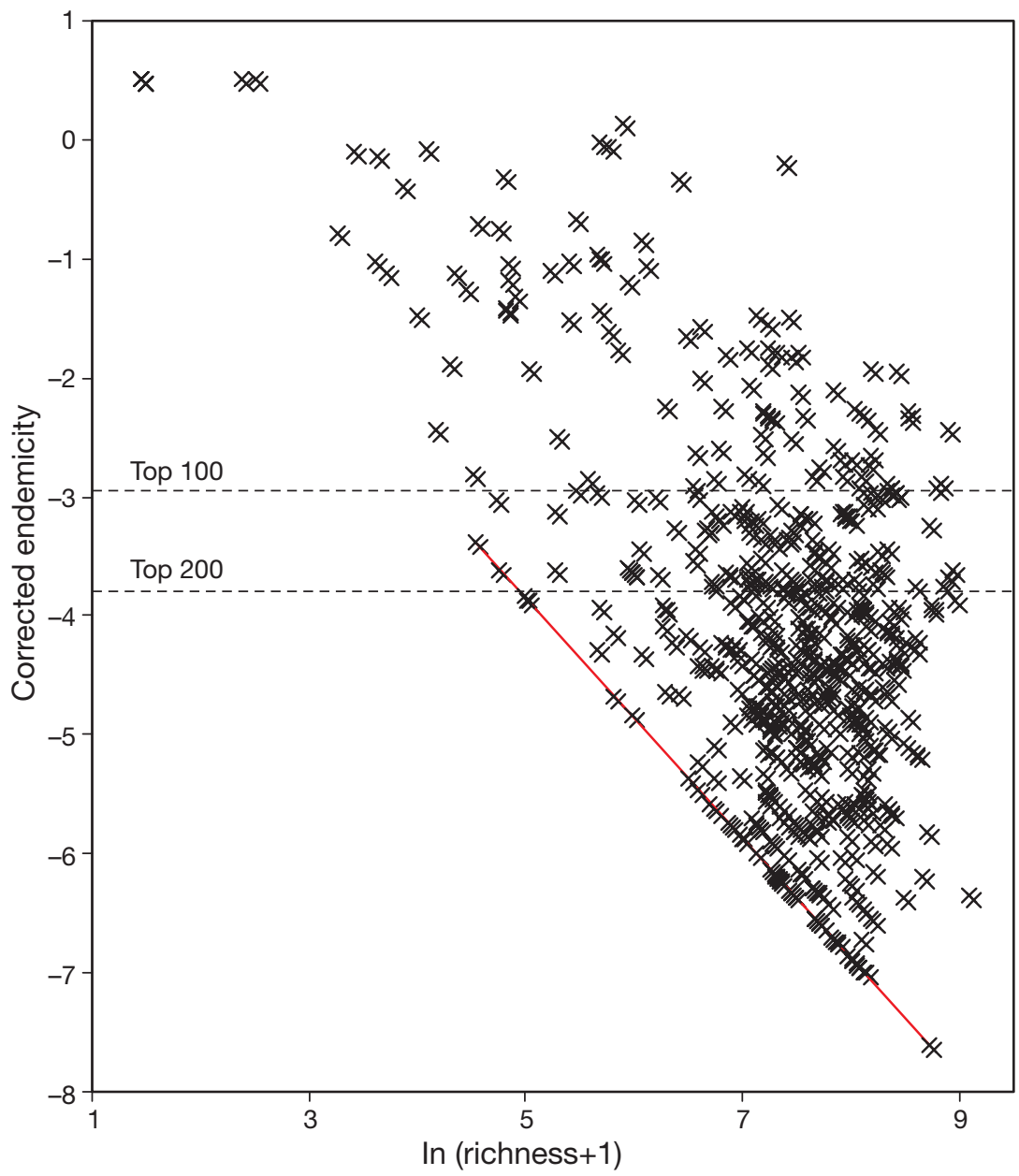

Fig. 3. Corrected endemicity versus ln species richness for all ecoregions. Corrected endemicity is the logit-transformed taxonomically adjusted endemicity. The diagonal line indicates the set of ecoregions that have only 1 endemic species. The dashed lines indicate the Top 100 and Top 200 ecoregions, respectively

defined as exactly and transparently as possible (Groves et al. 2002, Williams et al. 1998).

Like most prioritisation exercises we used the number of endemics as the key variable to identify highly irreplaceable regions. But, we have considered area and species richness in tandem, a procedure which most approaches use only implicitly (Brooks et al. 2006), and we have explicitly modelled the relationship between these variables. Our results indicate that endemicity, corrected for species richness, better explains the observed variance than absolute numbers of endemics or percentage, which have poor error structures. These results corroborate Fa et al.'s (2004) preliminary assessment of the relationship between endemic and non-endemic species in a subset of the data. Although the proportion of variance explained by logit endemicity, varies depending on the specific data set and areas used (endemicity explained by PC1 or PC2, respectively), we have shown here that the relationship is ro- bust and applicable to the global database. In fact, the use of the logit transformation, pioneered and made available by Crawley (1993), has been used by various authors to linearise the observed values of proportions.

Areas of high endemicity are special for conservation, because they are areas of significant past, and potentially future, speciation. Rosenweig (1995) postulates that such regions, created through the presence of geographical barriers, act as a 'speciation machine, rapidly cranking out new species'. Thus, areas which we have identified by their higher levels of endemism are those which have unique taxa at a level greater than any other site. We cannot argue here that we have a mechanism for identifying natural centres of evolution in the strictest sense, since we are aware of the difficulty involved in resolving the importance of isolation versus ecotonal influences (see Smith et al. 2005). However, compared to simply using the total number of endemics in a given area, our estimation of endemicity, in which we correct for species richness, stresses the process of speciation by ranking areas high if the proportion of endemics is high. We contend that focussing merely on total numbers of endemics may distract from the importance of those areas where the total number of endemics is low, but the proportion is relatively high.

A number of approaches other than ecoregions have been used to select areas of global endemicity, with paradigms varying from minimum species distribution ranges, as in Endemic Bird Areas (Stattersfield et al. 1998), to broad area delimitation in global biodiversity hotspots (Myers et al. 2000). Such analyses of endemism areas are widely recognised as timely advances in determining where conservation needs are greatest and where potential benefits of conservation may be maximised. Our method corroborates many of the biogeographic units identified by other approaches as high priority, and our resulting map (Fig. 5) corresponds to Myers et al. (2000), but there are also striking differences. Hotspots are based on regions containing at least 1500 species of vascular plants $(>0.5 \%$ of the world's total) as endemics, and to have lost at least $70 \%$ of its original habitat. Using these criteria, Myers (1988) first identified 10 tropical forest 'hotspots', later adding a further 8, including 4 Mediterranean-type 
A

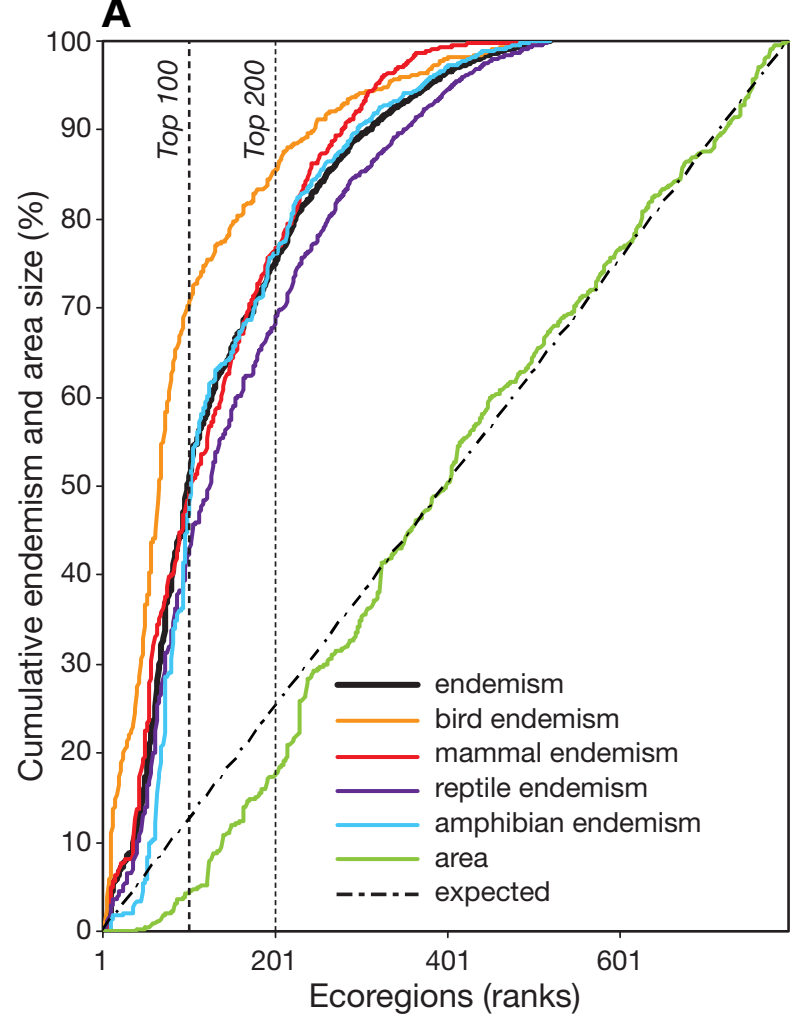

B

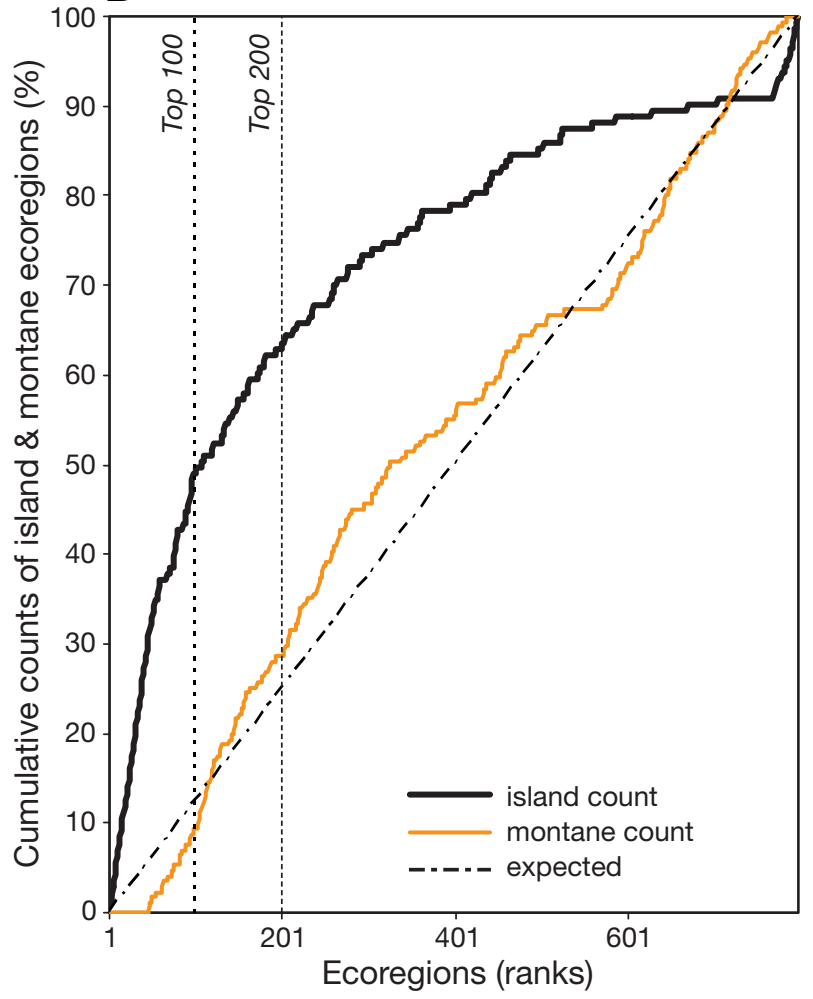

Fig. 4. Cumulative percentages of total endemism and area size for (A) all ecoregions and (B) island and montane types. Ecoregions are ranked according to logit endemicity. The Top 100 and Top 200 ecoregions are indicated by the vertical dotted lines

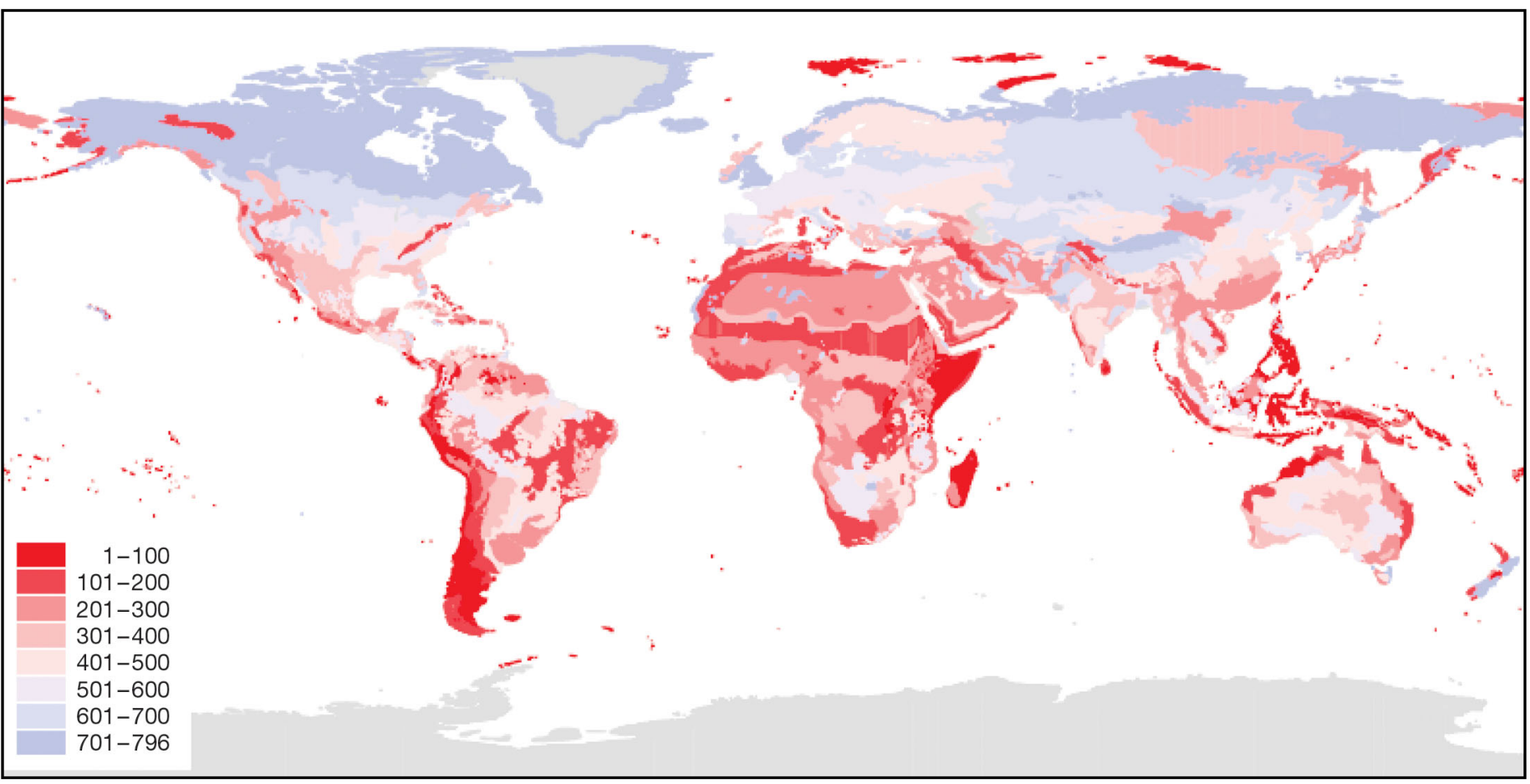

Fig. 5. World ecoregion map showing the distribution of ecoregions ranked according to corrected endemicity. Ecoregions are classified into groups of 100 
ecosystems (Myers 1990). A major revision of the concept undertaken in 1999 identified a total of 25 hotspots (Myers et al. 2000), but another 9 were added in a second reanalysis (Mittermeier et al. 2004). Mittermeier et al. (2004) argue that such increments in number of hotspots are due to growing data accuracy on some taxonomic groups (e.g. vertebrate species), and to major advances in the quantity and reliability of species distribution data. The hotspots map and our map differ in that ours highlights areas in temperate and arctic regions as well as in tropical realms, and picks out biologically important island areas (e.g. Galapagos) not included in hotspots until their last iteration. Hotspots are based on a threshold number of endemic plant species, and sometimes described using percentage endemism. Percentage endemism is a form of measurement widely used, but has drawbacks in that similar proportions of endemism can result from very different (and therefore biologically meaningful) species richness levels. Thus, within hotspots, Madagascar and the Indian Ocean Islands top the list with $81 \%$ of unique vertebrate species, despite the fact that species diversity is dramatically different in both areas.

Definition of endemism has proven difficult (Anderson 1994), and use of different definitions prevents direct comparison among regions (Peterson \& Watson 1998). We consider that counting species exclusively occurring within a specific ecoregion, as we have done, is a more precise way of mapping global endemicity than hotspots. Although there may be challenges in assigning boundaries to nature using ecoregions (see above) the boundary delimitation of hotspots currently remains unreported. Furthermore, hotspots range from areas of relatively homogenous environment (e.g. Brazilian cerrado), to vast regions containing a large number of habitats (e.g. Madagascar), hence making comparisons between hotspots relatively imprecise. Furthermore, clustering of endemics within the large multi-habitat hotspots occurs only within a small fraction of the total hotspot area. Interestingly, Mittermeier et al. (2004) argued that to facilitate analysis and collaboration the boundaries of the hotspots (and those of the high biodiversity wilderness areas) correspond directly to those of the WWF-US ecoregions.

We have re-confirmed that endemicity is affected positively by isolation, which we have simply described in terms of whether the ecoregions were montane or insular. Both island and montane endemicity were higher in all taxonomic groups, with the exception of amphibians on islands and mammals in montane areas. An interesting, but expected result was the obvious separation of island areas (either highest priority or lowest priority) from other ecoregions. The concentration of island ecoregions amongst the highest priority ecoregions emphasises the importance of islands as generators of new taxa, more so than other approaches (such as biodiversity hotspots, Global 200 or Endemic Bird Areas) have done. However, the spread of island ecoregions in our endemicity-richness plot reflects differing degrees of isolation (and colonisation dynamics) typical of islands worldwide (Sadler 1999). Such association between distance from source and endemicity was shown for Indo-Pacific islands in Fa et al. (2004). Given the greater vulnerability to which islands are prone, our analysis highlights their significant conservation value (Whittaker 1998).

The importance of islands in explaining endemicity differs depending on taxonomic group. For example, the absence of any correlation in our amphibian islandcontinent data likely reflects this group's dispersal limitations, in particular its sensitivity to salt water. The lack of significant differences between montane and non-montane mammalian endemicity may be explained by the fact that, for many mammals, mountains may be less of a geographical barrier.

Our approach furthers the identification of conservation priorities at a global scale, but we must highlight several caveats. First, we used ecoregions as units of analysis. Ecoregions vary largely in size, and the relation between size and species range might affect the identification of endemics. Thus, the comparison of proportions of endemics among ecoregions of different sizes, or among regions where the ecoregions differ systematically in size might be problematic. However, the effect is likely to be small as ecoregions are defined as natural units, and we used ecoregion area as a predictor in our models. Second, ecoregion lists may diverge in definition and detail (e.g. some Global 200 ecoregions, Olson \& Dinerstein 2002, are not listed in the WWF-US ecoregion data base) and there is considerable discussion as to which biogeographical model best identifies natural units of ecoregions (Jepson \& Whittaker 2002, Wikramanayake et al. 2002). Having said this, the WWF-US ecoregion approach is currently the most comprehensive representational system for ecosystem diversity and is increasingly being adapted for conservation management. It constitutes the basis of the World Wildlife Fund's conservation planning (Lamoreux et al. 2006) and the current hotspot boundaries have been clipped to match the ecoregion boundaries (Mittermeier et al. 2004). Third, the split of ecoregions into island versus continental areas may over-simplify the model, and further refinements are required, especially since evolution in archipelagos differs from isolated islands (Orme et al. 2005). Fourth, we considered only 4 classes of vertebrates. However, global patterns of species are highly correlated among amphibians, reptiles, birds and mammals (as shown in the bi-plot in Fig. 1), and the selection of regions for 
high levels of endemism also fulfils the conservation of non-endemics. Lamoreux et al. (2006) suggest that this is because regions selected for high endemism capture significantly more species than expected by chance. Therefore, patterns observed in these 4 vertebrate classes will also hold for other taxa, although this has not been explored in the present paper.

Ranking of ecoregions should be considered inclusive not exclusive. For example, the lowest priority ecoregions contain a large number of islands, all without any recorded endemics amongst mammals, birds, reptiles and amphibians. Endemic species amongst other taxa will change their ranking if used. For example, this may be the case for ecoregions such as the Hawaii tropical low shrublands and Chatham Island temperate forests (Ecoregion Codes OC0702 and AA0401, respectively; 13th lowest and lowest rank, respectively), which contain large numbers and substantially large proportions of endemic plants (National Geographic 2007a,b) but few or no vertebrate endemics. Conversely, Rapa Nui, containing the low-ranking ecoregion 'Rapa Nui subtropical broadleaf forests' (OC0111, 5th lowest rank), is in general characterised by faunal and floral poverty even in taxa not affected by human-mediated extinctions (Segers \& Dumont 1993); only a single endemic tree, now extinct, has been described (Maunder et al.1999).

Prioritisation of biodiversity centres for conservation is often critically dependent on the underlying value paradigms employed. Thus, no approach is ultimately a priori superior to alternative approaches. In the present paper, we have introduced a rank-based, prioritysetting scheme which clearly discerns global patterns of endemic species distribution, not in terms of absolute numbers, but as a function of how endemicity relates to underlying species richness. Here, we confirm through statistical analyses that endemicity levels are significantly correlated with geographic isolation and (as already well known) islands and mountains contribute disproportionately more new taxa. We consider our approach to be a framework for conservation action and targeted fundraising. However, we emphasise that the ranking system should not be regarded dogmatically. This is because data insufficiency and variance in patterns of endemism and species richness over time, space and taxonomic units will inevitably result in changes of rank positions once more data have been included and the model refined. More important perhaps, is the issue of whether another prioritisation scheme, like ours, will merely diversify rather than unify conservation efforts and misallocate conservation money and resources as suggested by Mace et al. (2000). However, although we agree with Kareiva \& Marvier (2003) that no prioritisation scheme is flawless, we argue that our method is a more refined way of de- tecting global endemism areas, and that by using this method we can assist in ensuring that such important areas are not overlooked.

Acknowledgements. First and foremost, we thank John Lamoreux, Colby Loucks, and the WWF-US for providing us with the species and ecoregions databases; John's constant support and encouragement is gratefully acknowledged. We are also most grateful to Robert W. Burn and Fiona M. Underwood of the Statistical Services Centre at the University of Reading, who performed all statistical analyses reported here. We thank Tim Wright for producing the colour map. Andy Purvis, Woody Turner, and 3 anonymous reviewers made useful comments on the manuscript.

\section{LITERATURE CITED}

Anderson S (1994) Area and endemism. Q Rev Biol 69:451471

Brooks TM, Mittermeier RA, da Fonseca GAB, Gerlach J and 5 others (2006) Global biodiversity conservation priorities. Science 313:58-61

Brummitt N, Lughadha EN (2003) Biodiversity: Where's hot and where's not. Conserv Biol 17:1442-1448

Collett DC (2002) Modelling binary data (2nd edn). Chapman \& Hall/CRC, London

Crawley MJ (1993) GLIM for ecologists. Blackwell Scientific, Oxford

Erwin TL (1991) An evolutionary basis for conservation strategies. Science 253:750-752

Fa JE, Burn RW, Stanley Price MR, Underwood FM (2004) Identifying important endemic areas using ecoregions: birds and mammals in the Indo-Pacific. Oryx 38:91-101

Groves CR, Jensen DB, Valutis LL, Redford KH and 6 others (2002) Planning for biodiversity conservation: Putting conservation science into practice. Bioscience 52:499-512

Henderson IM (1991) Biogeography without areas? Aust Syst Bot 4:59-71

Insightful Corporation (2001) S-PLUS 6 for Windows. Seattle, WA

Jepson P, WWhittaker RJ (2002) Ecoregions in context: a critique with special reference to Indonesia. Conserv Biol 16:42-57

Kareiva P, Marvier M (2003) Conserving biodiversity coldspots. Am Sci 911:344-351

Lamoreux JF, Morrison JC, Ricketts TH, Olson DM, Dinerstein E, McKnight MW, Shugart HH (2006) Global tests of biodiversity concordance and the importance of endemism. Nature 440:212-214

Mace GM, Balmford A, Boitani L, Cowlishaw G and 13 others (2000) It's time to work together and stop duplicating conservation efforts. Nature 405:393-393

Maunder M, Culham A, Bordeu A, Allainguillaume J, Wilkinson M (1999) Genetic diversity and pedigree for Sophora toromiro (Leguminosae): a tree extinct in the wild. Mol Ecol 8:725-738

McCullagh P, Nelder JA (1989) Generalized linear models (2nd edn). Chapman \& Hall/CRC, London

Mittermeier RA, Robles-Gil P, Mittermeier CG (eds) (1997) Megadiversity. Earth's biologically wealthiest nations. CEMEX/Agrupacion Sierra Madre, Mexico City

Mittermeier RA, Myers N, Thomsen JB, da Fonseca GAB, Olivieri S (1998) Biodiversity hotspots and major tropical wilderness: approaches to setting conservation priorities. Conserv Biol 12:516-520 
Mitterrmeier RA, Mittermeier CG, Brooks TM, Pilgrim JD, Konstant WR, da Fonseca GAB, Kormos C (2003) Wilderness and biodiversity conservation. Proc Natl Acad Sci USA 118:10309-10313

Mittermeier RA, Robles Gil P, Goettsch Mittermeier C, Brooks T, Hoffman M, Lamoreux J, da Fonseca GAB, Selligman P (2004) Hotspots revisited. Chicago University Press, Chicago, IL

Morrone J J (1994) On the identification of areas of endemism. Syst Biol 43:373-401

Myers NA (1988) Threatened biotas: 'hotspots' in tropical forests. Enviromentalist 8:187-208

Myers NA (1990) The biodiversity challenge: expanded hotspots analysis. Environmentalist 10:243-256

Myers N, Mittermeier RA, Mittermeier CG, da Fonseca GAB, Kent J (2000) Biodiversity hotspots for conservation priorities. Nature 403:853-858

National Geographic (2007a) Hawaii tropical low shrublands (OC0702) Available at: http://www. nationalgeographic.com/wildworld/profiles/terrestrial/ oc/oc0702.html

National Geographic (2007b) Chatman Island temperate forests (AA0401) Available at: http://www.nationalgeographic.com/wildworld/profiles/terrestrial/aa/aa0401.html

Olson DM, Dinerstein E (1998) The global 200: A representation approach to conserving the Earth's most biologically valuable ecoregions. Conserv Biol 12:502-515

Olson DM, Dinerstein E (2002) The Global 200: Priority ecoregions for global conservation. Ann Mo Bot Gard 89: 199-224

Olson DM, Dinerstein E, Wikramanayake ED, Burgess ND and 14 others (2001) Terrestrial ecoregions of the world: A new map of life on Earth. Bioscience 51:933-938

Orme CDL, Davies RG, Burgess M, Eigenbrod F and 11 others (2005) Global hotspots of species richness are not congruent with endemism or threat. Nature 436:1016-1019

Peterson AT, Watson DM (1998) Problems with areal definitions of endemism: the effects of spatial scaling. Divers Distrib 4:189-194

Platnick N (1991) On areas of endemism. Aust Syst Bot 4:11-13

Redford KH, Coppolillo P, Sanderson EW, Da Fonseca GAB and 10 others (2003) Mapping the conservation landscape. Conserv Biol 17:116-131

Editorial responsibility: Dave Hodgson,

Penryn, UK
Rosenweig ML (1995) Species diversity in space and time Cambridge. University Press, Cambridge

Sadler JP (1997) Biodiversity of oceanic islands: a palaeoecological assessment. J Biogeogr 26:75-87

Segers H, Dumont HJ (19993) Zoogeography of Pacific Ocean islands: a comparison of the rotifer faunas of Easter Island and the Galapagos archipelago. Hydrobiologia 1:475-480

Shi H, Singh A, Kant S, Zhu ZL, Waller E (2005) Integrating habitat status, human population pressure, and protection status into biodiversity conservation priority setting. Conserv Biol 19:1273-1285

Smith TB, Calsbeek R, Wayne RK, Holder KH, Pires D, Bardeleben C (2005) Testing alternative mechanisms of evolutionary divergence in an African rain forest passerine bird. J Evol Biol 18:257-268

Spector S (2002) Biogeographic crossroads as priority areas for biodiversity conservation. Conserv Biol 16:1480-1487

Stattersfield AJ, Crosby MJ, Long AJ, Wege DC (1998) Endemic bird areas of the world. BirdLife International, Cambridge

Szumik CA, Cuezzo F, Goloboff PA, Chalup AE (2002) An optimality criterion to determine areas of endemism. Syst Biol 51:806-316

Vane-Wright RI, Humphries CJ, Williams PH (1991) What to protect-systematics and the agony of choice. Biol Conserv 55:235-254

Whittaker RJ (1998) Island biogeography: ecology, evolution and conservation. Oxford University Press, Oxford

Wikramanayake E, Dinerstein E, Loucks CJ, Olson DM, Morrison J, Lamoreux J, McKnight M, Hedao P (2002) Terrestrial ecoregions of the Indo-Pacific: a conservation assessment. Island Press, Washington, DC

Williams PH (1998) Key sites for conservation: area-selection methods for biodiversity. In: Mace GM, Balmford A, Ginsberg JR (eds) Conservation in a changing world. Cambridge University Press, Cambridge, p 211-249

World Island Information (2006) World island information. Available at: www.worldislandinfo.com

World Wildlife Fund (2006) WildFinder: Online database of species distributions (Jan 06 edn). Available at: www. worldwildlife.org/wildfinder/

WWF \& IUCN (1994-7) Centres of plant diversity. A guide and strategy for their conservation (3 vols). IUCN Publications Unit, Cambridge

Submitted: January 30, 2007; Accepted: April 6, 2007 Proofs received from author(s): May 15, 2007 